\title{
Direct Electrochemistry and Electrocatalytic Behavior of Horseradish Peroxidase on Attapulgite Clay Modified Electrode
}

\author{
Huihui Chen, ${ }^{*} * *$ Zhe Zhang, ${ }^{* * *}$ Dongqing CaI, ${ }^{* *}$ Shengyi Zhang, ${ }^{*}$ Bailin Zhang,*** \\ Jilin TANG, ${ }^{* * * \dagger}$ and Zhengyan $\mathrm{WU}^{* * \dagger}$ \\ *School of Chemistry and Chemical Engineering, Anhui University, Hefei 230039, P. R. China \\ **Key Laboratory of Ion Beam Bioengineering, Hefei Institutes of Physical Science, \\ Chinese Academy of Sciences, Hefei 230031, P. R. China \\ ***State Key Laboratory of Electroanalytical Chemistry, Changchun Institute of Applied Chemistry, \\ Chinese Academy of Sciences, Changchun 130022, P. R. China
}

\begin{abstract}
A novel third-generation hydrogen peroxide $\left(\mathrm{H}_{2} \mathrm{O}_{2}\right)$ biosensor was developed by immobilizing horseradish peroxidase (HRP) on a biocompatible attapulgite (ATP) modified glassy carbon (GC) electrode. The ATP could provide a biocompatible microenvironment for enzyme molecules, greatly amplify the coverage of HRP molecules on the electrode surface, and most importantly facilitate the direct electron transfer between HRP and the electrode. The biosensor construction process was followed by atomic force microscopy (AFM). Cyclic voltammetry was employed to characterize the properties of the biosensor. A linear calibration plot of the enzyme electrode was obtained over the range of $5 \mu \mathrm{M}$ to $0.3 \mathrm{mM}$ for $\mathrm{H}_{2} \mathrm{O}_{2}$ with a detection limit of $5 \mu \mathrm{M}$. Furthermore, the biosensor showed high sensitivity, good reproducibility, and fine long-term stability.
\end{abstract}

(Received February 18, 2011; Accepted March 14, 2011; Published June 10, 2011)

\section{Introduction}

The feasibility of heterogeneous direct electron transfer (DET) reactions between redox proteins and the electrode surface has attracted considerable interest; an understanding of these reactions fundamentally can establish a desirable model for studying the redox behavior of the proteins in biological systems. ${ }^{1}$ Among numerous redox proteins, horseradish peroxidase (HRP) has commonly been chosen to construct $\mathrm{H}_{2} \mathrm{O}_{2}$ biosensors because of easy availability in high purity and low cost. An electrochemical technique based on a simple and low-cost enzyme electrode has been extensively employed for the determination of $\mathrm{H}_{2} \mathrm{O}_{2}$ for its simplicity, high selectivity and intrinsic sensitivity. ${ }^{2}$

However, the direct electron-transfer rate of redox proteins is rather slow at conventional electrodes. This slow electron exchange may be caused by an unsuitable orientation of proteins on the electrode surface, which increases the distance between the electroactive center of the protein and the electrode surface. Moreover, the adsorption of impurities and denatured protein onto an electrode surface could block electron communication between heme and the electrode. ${ }^{3}$ Therefore, one of the main challenges is to select a host matrix to provide a suitable microenvironment for the proteins, and to enhance direct electron transfer between the proteins and the underlying electrodes. ${ }^{4}$ Until now, many materials, such as polymer films, ${ }^{5}$ nano-particles, ${ }^{6-8}$ biomembranes, ${ }^{9}$ surfactants ${ }^{10}$ and clay ${ }^{11-13}$ have been used to promote the electron transfer between redox

† To whom correspondence should be addressed.

E-mail: zywu@ipp.ac.cn; jltang@ ciac.jl.cn proteins and electrodes. Composite enzyme-clay films have been confirmed to improve the analytic performances, including adhesion, mechanical strength and enzymatic activity. ${ }^{14-16}$

Attapulgite (ATP), as one kind of clay, has unique physical and chemical properties, and is receiving increasing attention in many areas, such as inorganic-organic polymer hybrids, fertilizer suspensions, drilling fluids, oil refining, catalysts, catalyst supports, the pharmaceutical industry and others. ${ }^{17-20}$ Many national pharmacopoeias have even accepted ATP. In addition, ATP has fine biological affinity, which makes it friendly to enzymes. $^{21,22}$ In a word, there are many reasons why we may choose ATP as the matrix for enzyme immobilization: low cost, high chemical stability, high ion-exchange properties, unique aluminosilicate-layered structure with appreciable surface area, and especially fine biological affinity. ${ }^{23,24}$

In this paper, ATP was used as a matrix for HRP immobilization on the surface of a glassy carbon (GC) electrode, and the direct electron exchange between HRP and the electrode was studied. Meanwhile, HRP retains its bioactivity and displays a high affinity for $\mathrm{H}_{2} \mathrm{O}_{2}$, producing a novel reagentless sensor for the measurement of $\mathrm{H}_{2} \mathrm{O}_{2}$. Compared with conventional second generation sensors, this DET-based sensor has some practical advantages, including operation simplicity, low expense of fabrication and suitability for real-time detection.

\section{Experimental}

\section{Reagents}

HRP was purchased from Sigma (USA) and used as received. ATP was obtained from Jiangsu Junda AT Material Co., Ltd. (Jiangsu, China). Additions of $\mathrm{H}_{2} \mathrm{O}_{2}$ were made from a $100 \mathrm{mM}$ 


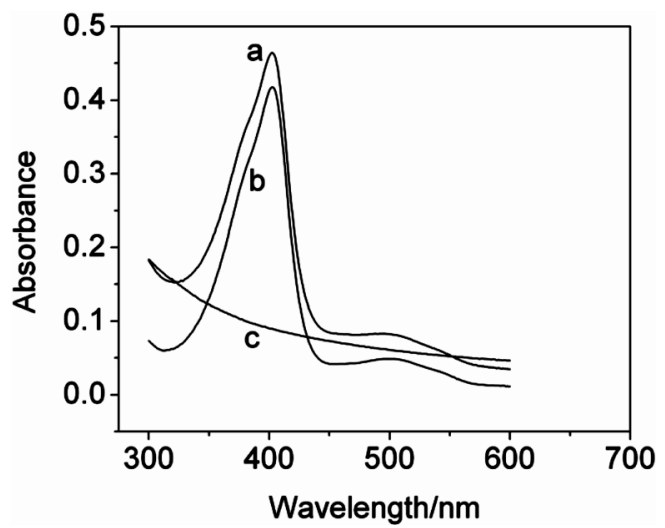

Fig. 1 UV-Vis absorption spectra of samples in $0.1 \mathrm{M} \mathrm{pH}$ 7.0 PBS: (a) HRP, (b) HRP/ATP composite, (c) ATP.

stock solution, prepared by dilution from a solution obtained from Beijing Chemical Reagent (Beijing, China) (30\% w/w in water, $99 \%$ purity). The stock solution was prepared daily so as to avoid excessive decomposition of the $\mathrm{H}_{2} \mathrm{O}_{2}$ to water and oxygen. Phosphate buffer solutions (PBS) were prepared by mixing stock standard solutions of $\mathrm{Na}_{2} \mathrm{HPO}_{4}$ and $\mathrm{NaH}_{2} \mathrm{PO}_{4}$. Other chemicals were of analytical reagent grade. All solutions were prepared with pure water obtained by means of a Milli-Q water purification set.

\section{Characterizations and electrochemical measurements}

The UV-Vis spectra of the HRP solution, ATP suspension and HRP/ATP composite suspension were measured with a Cary 50 Scan UV-Vis spectrophotometer (Varian, USA). The morphology of ATP and HRP/ATP was recorded using an SPI3800N microscope (Seiko Instruments, Japan) in the tapping mode. All electrochemical experiments were performed by a CHI 660 (USA) electrochemical workstation using a conventional three-electrode system consisting of a modified GC electrode as a working electrode, a saturated calomel electrode (SCE) as a reference electrode and a platinum wire as an auxiliary electrode. The electrolyte was deoxygenated by purging pure nitrogen into the solution for about $30 \mathrm{~min}$, and nitrogen gas was kept flowing over the solution during electrochemical experiments.

\section{Preparation of the biosensor}

A GC electrode (3 $\mathrm{mm}$ in diameter) was polished to a mirror-like surface with fine emery papers and 1.0, 0.3 and $0.05 \mu \mathrm{m}$ alumina slurry, followed by thoroughly rinsing with Milli-Q water. The electrode was then successively sonicated in alcohol and Milli-Q water, and allowed to dry at room temperature. Then, $5 \mu \mathrm{l}$ of a $1 \mathrm{mg} / \mathrm{ml}$ purified ATP sample prepared as previously described ${ }^{18}$ was directly dropped onto a pretreated GC electrode and dried at room temperature for $3 \mathrm{~h}$ to make an ATP modified GC electrode. A 5- $\mu$ l aliquot of HRP $(5 \mathrm{mg} / \mathrm{ml}$, in $\mathrm{pH}$ 7.0 PBS) was dropped onto the surface of the ATP modified GC electrode, and then the electrode was dried at room temperature and rinsed with Milli-Q water twice to remove any non-firmly adsorbed HRP. The obtained HRP/ATP/GC electrode was stored at $4^{\circ} \mathrm{C}$ in a refrigerator when not in use.
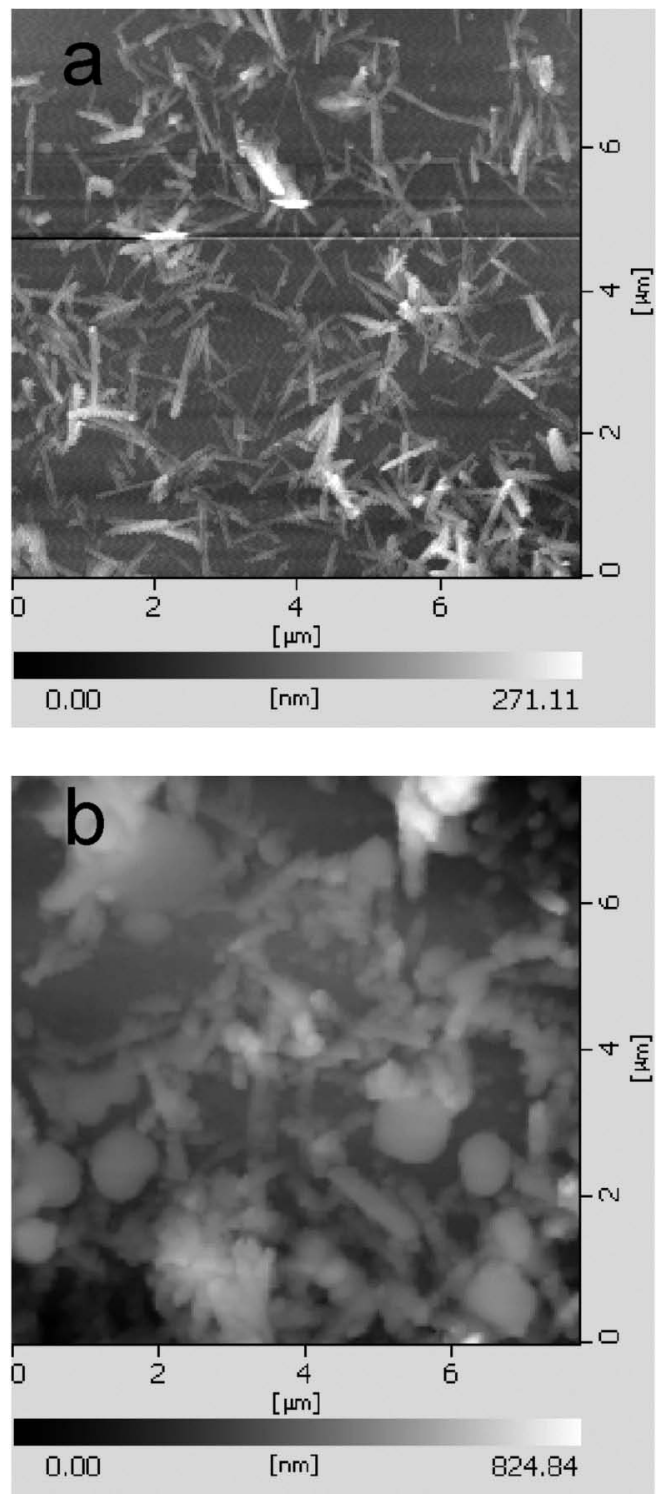

Fig. 2 AFM images of (a) ATP, (b) ATP with adsorbed HRP molecules.

\section{Results and Discussion}

\section{$U V$-Vis absorption spectroscopic characterization}

UV-Vis spectroscopy is a useful tool for monitoring any possible change of the Soret absorption band of HRP. ${ }^{25}$ Figure 1 shows the UV-Vis spectra of a HRP and HRP/ATP composite in $\mathrm{pH}$ 7.0 PBS. The native HRP gave a heme band at $402 \mathrm{~nm}$ (curve a). For the HRP/ATP composite, the absorption band was also at $402 \mathrm{~nm}$ (curve b). This indicates that ATP does not destroy the proteins' structure, or change the fundamental microenvironment. It can also be concluded that as a matrix for the immobilization of protein, ATP will undoubtedly maintain the properties and reactivity of the protein.

\section{AFM characterization of the biosensor construction}

We used AFM to study the interaction between HRP and ATP. AFM images confirmed that the HRP molecules had been immobilized on ATP. Figure 2a shows the ATP without HRP molecules and Fig. $2 b$ shows that with adsorbed HRP molecules. 


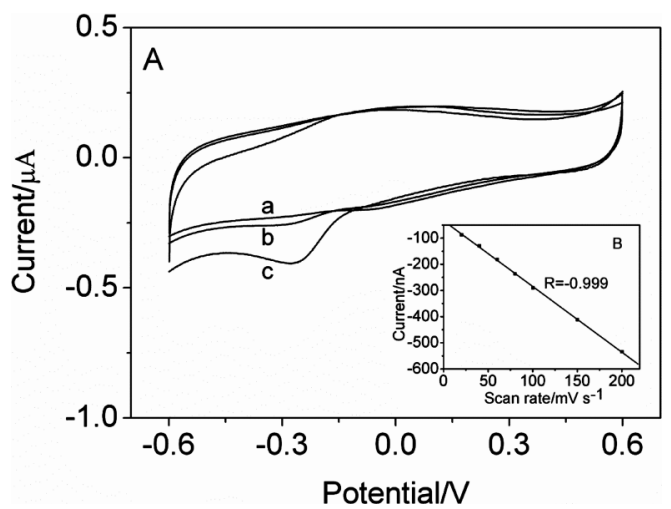

Fig. 3 (A) Cyclic voltammograms of electrodes in $0.1 \mathrm{M}$ PBS (pH 6.0): (a) ATP/GC electrode, (b) HRP/GC electrode, (c) HRP/ATP/GC electrode. Scan rate: $50 \mathrm{mV} / \mathrm{s}$. (B) Dependence of the cathodic peak current of the HRP/ATP/GC electrode on the scan rate. Scan rates: 20, 40, 60, 80, 100, 150 and $200 \mathrm{mV} / \mathrm{s}$.

Comparing the two images, it can be directly observed that HRP molecules are mostly adsorbed onto the surface of ATP. To obtain the sample of Fig. 2b, HRP in pH 7.0 PBS was directly dropped onto the ATP and dried at room temperature, and then rinsed with Milli-Q water twice to remove any non-firmly adsorbed HRP. At pH 7.0, HRP (isoelectric point: 8.9) has a net positive surface charge ${ }^{26}$ and ATP (isoelectric point: 3.0 ) has a net negative surface charge. ${ }^{27}$ Therefore, electrostatic interactions between the positively charged HRP and the negatively charged ATP make HRP to be adsorbed on the ATP. However, we also believe that some HRP could be adsorbed in the inner space of ATP because the ATP rod is porous, ${ }^{27}$ with a large specific surface area, and possibly able to entrap HRP. These results indicate that the ATP can be used as a support for HRP.

The electrochemical characteristics of the different $G C$ electrodes Figure 3A shows cyclic voltammograms of the ATP/GC electrode, HRP/GC electrode (HRP dropped onto the pretreated $\mathrm{GC}$ electrode and dried at room temperature for $3 \mathrm{~h}$ ) and $\mathrm{HRP} / \mathrm{ATP} / \mathrm{GC}$ electrode in $0.1 \mathrm{M} \mathrm{pH} 6.0 \mathrm{PBS}$ at $50 \mathrm{mV} / \mathrm{s}$. No distinct peak was observed at either the ATP/GC electrode (curve a) or HRP/GC electrode (curve b). However, a pair of cathodic-anodic peaks, $E_{\mathrm{pa}}$ and $E_{\mathrm{pc}}$ values at -0.05 and $-0.27 \mathrm{~V}$, were observed at the HRP/ATP/GC electrode (curve c). This pair of peaks are attributed to direct electron transfer between the heme group of HRP immobilized in the ATP films and the GC electrode. To further investigate the characteristics of the HRP/ATP/GC electrode surface, the effect of the scan rate on the response of immobilized HRP is shown in detail. It can be seen from Fig. $3 \mathrm{~B}$ that the reduction peak currents increase linearly with scan rates, indicating that the redox process is a surface-controlled electrode process. In this work the electron transfer of HRP immobilized in the ATP film may be enhanced. This was possibly because the heme group of HRP in ATP films achieves a favorable orientation, which makes the heme group more easily exposed to the surface of the electrode. ${ }^{28,29}$ Therefore, the electron-transfer process between the protein and the electrode could be promoted by an electron-hopping mechanism. ${ }^{30}$

Electrocatalytic behavior of HRP/ATP/GC electrode to the reduction of $\mathrm{H}_{2} \mathrm{O}_{2}$

Figure 4 shows cyclic voltammograms of the HRP/ATP/GC electrode in $0.1 \mathrm{M} \mathrm{pH}$ 6.0 PBS in both the presence and the

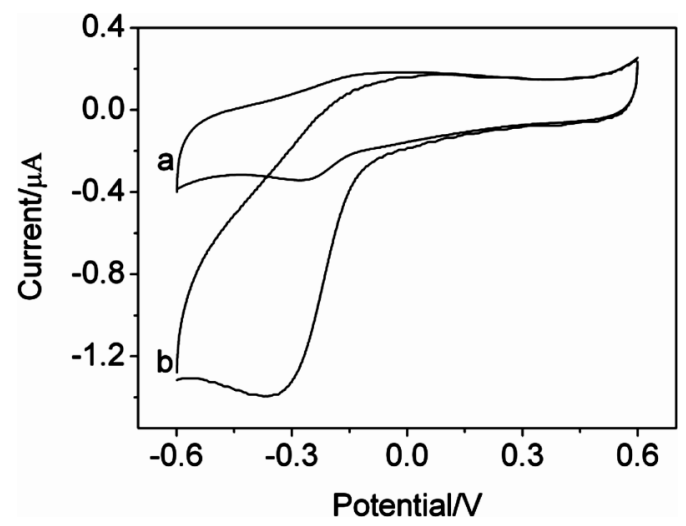

Fig. 4 Cyclic voltammograms of HRP/ATP/GC electrode in $0.1 \mathrm{M}$ PBS (pH 6.0) containing: (a) $0 \mathrm{M} \mathrm{H}_{2} \mathrm{O}_{2}$, (b) $50 \mu \mathrm{M} \mathrm{H}_{2} \mathrm{O}_{2}$. Scan rate: $50 \mathrm{mV} / \mathrm{s}$

absence of $\mathrm{H}_{2} \mathrm{O}_{2}$. When $\mathrm{H}_{2} \mathrm{O}_{2}$ was added, compared with the system with no $\mathrm{H}_{2} \mathrm{O}_{2}$ present, the cathodic peak current of the electrode increased dramatically, and the anodic peak almost disappeared. This catalytic reduction behavior for hydrogen peroxide shows the similarity with that of hemoglobin on the ATP. ${ }^{21}$ Thus, the catalytic mechanism of HRP immobilized in the ATP films to $\mathrm{H}_{2} \mathrm{O}_{2}$ reduction may be explained by the following process: ${ }^{31}$

$$
\begin{aligned}
& \mathrm{H}_{2} \mathrm{O}_{2}+\mathrm{HRP} \longrightarrow \mathrm{H}_{2} \mathrm{O}+\text { compound-I, } \\
& \text { Compound-I }+\mathrm{e}^{-} \longrightarrow \text { compound-II, } \\
& \text { Compound-II }+\mathrm{e}^{-} \longrightarrow \text { HRP. }
\end{aligned}
$$

In the first $2 \mathrm{e}^{-}$step, hydrogen peroxide is reduced to water and the bound cofactor is oxidized. This oxidized form of peroxidase is usually denoted as compound-I. Compound-I is then reduced in the first $1 \mathrm{e}^{-}$step to form compound-II. Compound-II is reduced in the second $1 \mathrm{e}^{-}$step back to HRP. According to studies, ${ }^{32}$ compound-II shows a higher stability than compound-I, and thus the reduction process of compound-II to native HRP is slow, so the third step can be detected by cyclic voltammetry. These results indicate that HRP incorporated into the ATP films can catalyze the reduction of $\mathrm{H}_{2} \mathrm{O}_{2}$ efficiently and still retain its biological activity.

\section{Amperometric response to $\mathrm{H}_{2} \mathrm{O}_{2}$}

To evaluate the dependence of the electrocatalytic current on the concentration of $\mathrm{H}_{2} \mathrm{O}_{2}$, the characteristics of the HRP/ATP/GC electrode were investigated by a chronoamperometric measurement at $\mathrm{pH}$ 6.0. The results presented in Fig. 5 indicate that the electrocatalytic current increases with increasing concentration of $\mathrm{H}_{2} \mathrm{O}_{2}$. The linear range between the electrocatalytic current and the concentration of $\mathrm{H}_{2} \mathrm{O}_{2}$ can extend to $0.3 \mathrm{mM}$. The correlation coefficient, $R$ is 0.997 , and the detection limit value is $5 \mu \mathrm{M}$, which imply that the HRP/ATP/GC electrode exhibits a higher affinity for $\mathrm{H}_{2} \mathrm{O}_{2}$.

\section{Reproducibility and stability}

The repeatability of the current response of the same enzyme electrode was examined in the presence of $50 \mu \mathrm{M} \mathrm{H}_{2} \mathrm{O}_{2}$ in $0.1 \mathrm{M}$ PBS. The relative standard deviation (RSD) was $3.6 \%$ for seven successive assays. The electrode-to-electrode reproducibility was determined in the presence of $50 \mu \mathrm{M} \mathrm{H}_{2} \mathrm{O}_{2}$ 


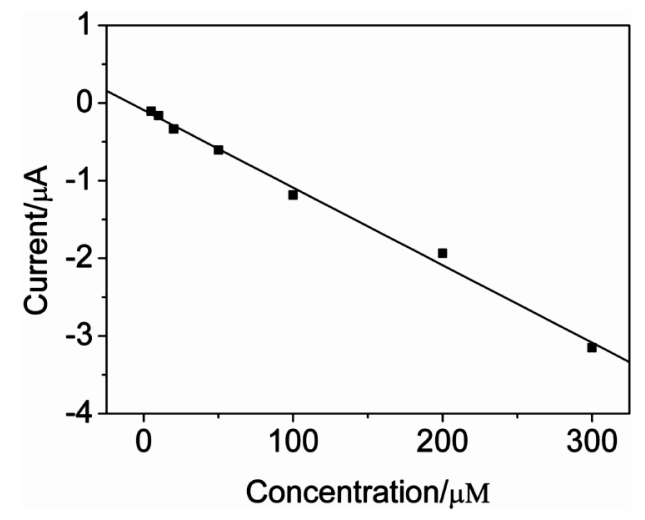

Fig. 5 Dependence of the electrocatalytic current on the concentration of $\mathrm{H}_{2} \mathrm{O}_{2}$.

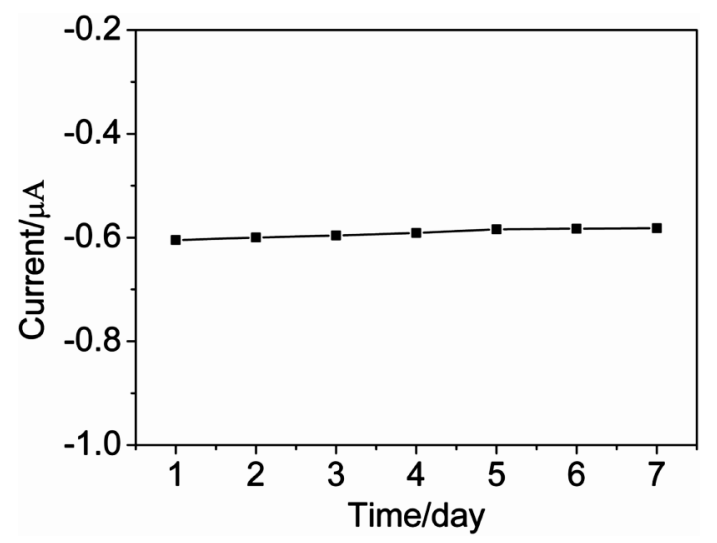

Fig. 6 Storage stability of the sensor: daily current response of the HRP/ATP/GC electrode to $50 \mu \mathrm{M} \mathrm{H}_{2} \mathrm{O}_{2}$ in $0.1 \mathrm{M}$ phosphate buffer (pH 6.0) during a 7-day period. Scan rate: $50 \mathrm{mV} / \mathrm{s}$.

in 0.1 M PBS with seven different enzyme electrodes. They yielded a 5.1\% RSD. When the biosensor was stored in the refrigerator at $4{ }^{\circ} \mathrm{C}$ and measured every day during a 7-day period, there was no obvious change of current in the response to $50 \mu \mathrm{M} \mathrm{H}_{2} \mathrm{O}_{2}$, as shown in Fig. 6. The good reproducibility and good stability might be due to the fact that HRP molecules were firmly immobilized in the ATP, which provided a biocompatible microenvironment on the electrode surface.

\section{Conclusion}

ATP was used as a matrix to modify the GC electrode. HRP could be effectively immobilized on the matrix to produce a fast direct electron transfer and to retain its bioactivity and native structure. The resulted enzyme electrode showed high sensitivity, good reproducibility and fine long-term stability. This approach provides a simple method to develop a new kind of electrochemical $\mathrm{H}_{2} \mathrm{O}_{2}$ biosensor.

\section{Acknowledgements}

The authors acknowledge financial support from the National Natural Science Foundation of China (No. 10975154).

\section{References}

1. M. F. Chaplin and C. Bucke, "Enzyme Technology", 1990, Cambridge University Press, Cambridge.

2. E. Ferapontova, K. Schmengler, T. Börchers, T. Ruzgas, and L. Gorton, Biosens. Bioelectron., 2002, 17, 953.

3. M. A. Cole, N. H. Voelcker, H. Thissen, and H. J. Griesser, Biomaterials, 2009, 30, 1827.

4. F. W. Scheller, N. Bistolas, S. Liu, M. Jänchen, M. Katterle, and U. Wollenberger, Adv. Colloid Interface, 2005, 116, 111.

5. Y. M. Li, H. H. Liu, and D. W. Pang, J. Electroanal. Chem., 2004, 574, 23.

6. L. Wang and E. K. Wang, Electrochem. Commun., 2004, 6, 225.

7. C. Xiang, Y. Zou, L. X. Sun, and F. Xu, Talanta, 2007, 74, 206.

8. L. Zhang, X. Jiang, E. K. Wang, and S. J. Dong, Biosens. Bioelectron., 2005, 21, 337.

9. J. Tang, J. G. Jiang, Y. H. Song, Z. Q. Peng, Z. Y. Wu, S. J. Dong, and E. K. Wang, Chem. Phys. Lipids, 2002, 120, 119.

10. E. V. Ivanova and E. Magner, Electrochem. Commun., 2005, 7, 323.

11. J. J. Feng, J. J. Xu, and H. Y. Chen, Biosens. Bioelectron., 2007, 22, 1618.

12. Z. Li and N. F. Hu, J. Electroanal. Chem., 2003, 558, 155.

13. E. Lojou, M. T. Giudici-Orticoni, and P. Bianco, $J$. Electroanal. Chem., 2005, 579, 199.

14. H. Huang, N. F. Hu, Y. H. Zeng, and G. Zhou, Anal. Biochem., 2002, 308, 141.

15. S. Kröning, F. W. Scheller, U. Wollenberger, and F. Lisdat, Electroanalysis, 2004, 16, 253.

16. J. M. Xu, W. X. Han, Q. F. Yin, J. Song, and H. Zhong, Chin. J. Chem., 2009, 27, 2197.

17. A. Al-Futaisi, A. Jamrah, A. Al-Rawas, and S. Al-Hanai, Environ. Geol., 2007, 51, 1317.

18. D. Q. Cai, Z. Y. Wu, J. Jiang, K. J. Ding, L. P. Tong, P. K. Chu, and Z. L. Yu, Nanotechnology, 2009, 20, 255302.

19. J. Chen and Y. Jin, Bioelectrochemistry, 2011, 80, 151.

20. S. Lai, L. Yue, X. F. Zhao, and L. J. Gao, Appl. Clay Sci., 2010, 50, 432.

21. G. B. Mahady, T. L. Dog, M. L. Barrett, M. L. Chavez, P. Gardiner, R. Ko, R. J. Marles, L. S. Pellicore, G. I. Giancaspro, and D. N. Sarma, Menopause, 2008, 15, 628.

22. J. M. Xu, W. Li, Q. F. Yin, H. Zhong, Y. L. Zhu, and L. T. Jin, J. Colloid Interface, Sci., 2007, 315, 170.

23. J. M. Xu, W. Li, Q. F. Yin, and Y. L. Zhu, Electrochim. Acta, 2007, 52, 3601.

24. P. K. Ghosh and A. J. Bard, J. Am. Chem. Soc., 1983, 105, 5691.

25. C. Mousty, Appl. Clay Sci., 2004, 27, 159.

26. A. Schejter, A. Lanir, and N. Epstein, Arch. Biochem. Biophys., 1976, 174, 36.

27. Q. S. Meng, Z. L. Shi, and S. H. Wang, Bull. Chin. Ceram. Soc., 2008, 27, 996.

28. J. Z. Xu, J. J. Zhu, Q. Wu, Z. Hu, and H. Y. Chen, Electroanalysis, 2003, 15, 219.

29. E. S. Ribeiro, S. L. P. Dias, S. T. Fujiwara, Y. Gushikem, and R. E. Bruns, J. Appl. Electrochem., 2003, 33, 1069.

30. S. S. Rosatto, P. T. Sotomayor, L. T. Kubota, and Y. Gushikem, Electrochim. Acta, 2002, 47, 4451.

31. L. Gorton, G. Jonsson-Pettersson, E. Csoregi, K. Johansson, E. Dominguez, and G. Marko-Varga, Analyst, 1992, 117, 1235.

32. X. Chen, C. Ruan, J. Kong, and J. Deng, Anal. Chim. Acta, 2000, 412, 89. 